\title{
RELATIVE MEASUREMENT IN VIVO OF ACCUMULATION OF RADIOIODINE BY THE HUMAN THYROID GLAND: COMPARISON WITH RADIOACTIVITY IN PERIPHERAL TISSUES ${ }^{1}$
}

\author{
By THOMAS J. LUELLEN, 2 F. RAYMOND KEATING, JR., MARVIN M. D. \\ WILLIAMS, JOSEPH BERKSON, MARSCHELLE H. POWER, \\ AND WILLIAM M. MCCONAHEY 2
}

(From the Divisions of Biochemistry, Biometry and Medical Statistics, Biophysics, and Medicine, Mayo Clinic and Mayo Foundation, Rochester, Minnesota)

(Received for publication July 29, 1948)

The gamma rays produced by radioiodine permit its direct measurement in vivo, and particularly in the thyroid gland, both of the human subject and of animals, with little or no disturbance of existing equilibriums, provided, that is, that the possibility of a biologic effect of radioiodine due to its radiation per se is disregarded. Full realization of the possibilities of this quantitative method of measurement has been thwarted by difficulties of interpreting the observations as well as by numerous technical difficulties which interfere with accuracy in the absolute measurement of radioiodine in vivo. These difficulties include geometric problems arising from anatomic variations in the thyroid and surrounding structures and the problem of evaluating the degree of absorption and scattering of radiation that occurs. However, in spite of the foregoing considerations. relative measurements over the thyroid, expressed simply in counts per second, have yielded useful data.

Hamilton and Soley (1) studied the collection of $\mathrm{I}^{131}$ by the thyroid in 17 subjects after administration of the radioiodine with $14 \mathrm{mg}$. of inert iodide as carrier. Data from normal individuals were recorded in smooth curves which reached a plateau about two days after administration of the dose and thereafter remained flat. Curves of collection for patients with nontoxic goiters resembled those of normal persons but larger quantities of radioiodine were collected. Thyrotoxic glands had a maximal uptake of $\mathrm{I}^{131}$ in one to four hours and the uptake then fell rapidly in 24 hours to one half to one fifth the maximal value.

1 Abridgment of thesis submitted by Dr. Luellen to the Faculty of the Graduate School of the University of Minnesota in partial fulfillment of the requirements for the degree of Master of Science in Medicine.

2 Fellow in Medicine, Mayo Foundation.
A nontoxic goiter in a child who had hypothyroidism showed a curve like that produced by the thyrotoxic glands and the thyroid glands of four children having hypothyroidism without goiter collected only a small amount of radioiodine. Later Hamilton (2) reported that, when $0.1 \mu \mathrm{g}$. instead of $14 \mathrm{mg}$. of iodide was used as carrier, the maximal uptake in hyperthyroid glands was several times greater and the rapid loss of radioiodine from the thyroid previously observed did not occur. In 1943, Hamilton and his associates (3) reported that the thyroids of two children who had hypothyroidism and goiters collected and retained relatively large amounts of radioiodine. Hertz (4) in 1941 made in vivo measurements over the thyroid region and found that the uptake of radioiodine in untreated hyperplastic thyroid glands approached 100 per cent.

Quimby and McCune (5) in 1947 made in vivo measurements of radioiodine in children. The mean collection by normal subjects was 12 per cent of the dose. The thyroids of hyperthyroid patients collected substantially more than this whereas hypofunctioning glands collected less than 1 per cent of the dose. Stanley and Astwood (6) in 1947 administered $I^{131}$ in doses of 100 microcuries without carriers to normal subjects for the purpose of assaying antithyroid compounds. When the counts per second recorded over the thyroid were plotted against the square root of time, the observations could be fitted to a straight line, from which was calculated an arbitrary numerical value which they called an "accumulation gradient." The value of this gradient in euthyroid subjects varied from 1.4 to 36.4 with a mean value of 9.4 .

Keating, Power, Berkson and Haines (7) have described studies on the excretion of radioiodine in the urine of human subjects. They indicated 
that neither the proportion of a close of radioiodine eventually excreted in the urine (the renal fraction) nor the rate constant estimated from the curve of urinary excretion could be regarded as direct or quantitative measures of the function of the kidney with regard to excretion of iodine. The former they felt to be a relative quantity depending on the capacity of the thyroid and of other tissues to dispose of iodine as well as of the kidney to excrete it, and the latter they inferred to be the rate of disappearance of radioiodine from blood. McConahey and co-workers (8) confirmed the latter assumption by showing that no significant difference existed between the rate of disappearance of radioiodine from blood, as determined directly by examination of the blood itself, and the rate of disappearance obtained from simultaneous observations on urine. The measure of renal excretion of radioiodine was shown to be the product of the renal fraction and the rate of disappearance of radioiodine from blood.

Keating and associates inferred from their analysis of urinary excretion that the same consiclerations would apply to the accumulation of radioiodine by the thyroid; namely, that both the proportion of a dose of radioiodine eventually collected by the thyroid, and the rate constant derived from a curve of radioiodine accumulation by the thyroid, would prove to be indirect and relative rather than direct and quantitative measures of the function of the thyroid with respect to accumulation of iodine.

It was the purpose of our investigation to apply the foregoing considerations directly to in vivo measurement of radioiodine in the thyroid of human beings and, particularly, to compare the kinetic behavior of radioiodine in the thyroid itself with observations in vivo on peripheral tissues, the concentration of radioiodine in the blood and the urinary excretion of this substance.

\section{METHODS AND MATERIALS}

The Geiger counter tubes ${ }^{3}$ used contained mica windows of approximately $3 \mathrm{mg}$. per square centimeter or about $0.01 \mathrm{~mm}$. thick and $3.0 \mathrm{~cm}$. in diameter. Counts were recorded by means of a scaling circuit with a scale of 256. The principle of a shield as described by Seidlin ct al. (9) was used; this consisted of a solid lead cylinder $5.2 \mathrm{~cm}$. thick and $11.5 \mathrm{~cm}$. in diameter to interpose be-

3 Manufactured by the Radiation Counter Laboratories.

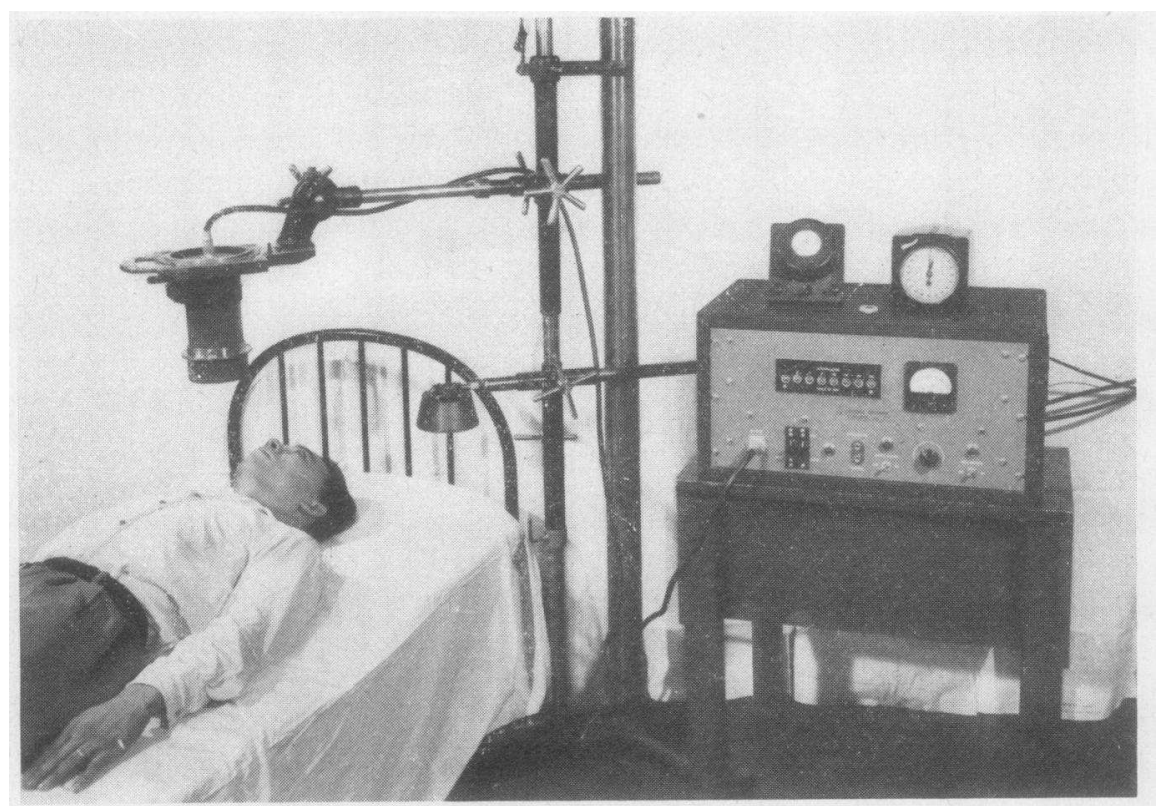

Fig. 1. Apparites for in Vivo Measurement of Radiolodine in the Thyroid with a Geiger Counter

Note shielded counter tube mounted on a roentgen-ray tube standard, movable shield to be interposed between the thyroid and the window of the counter, scaling circuit and recording clock. 


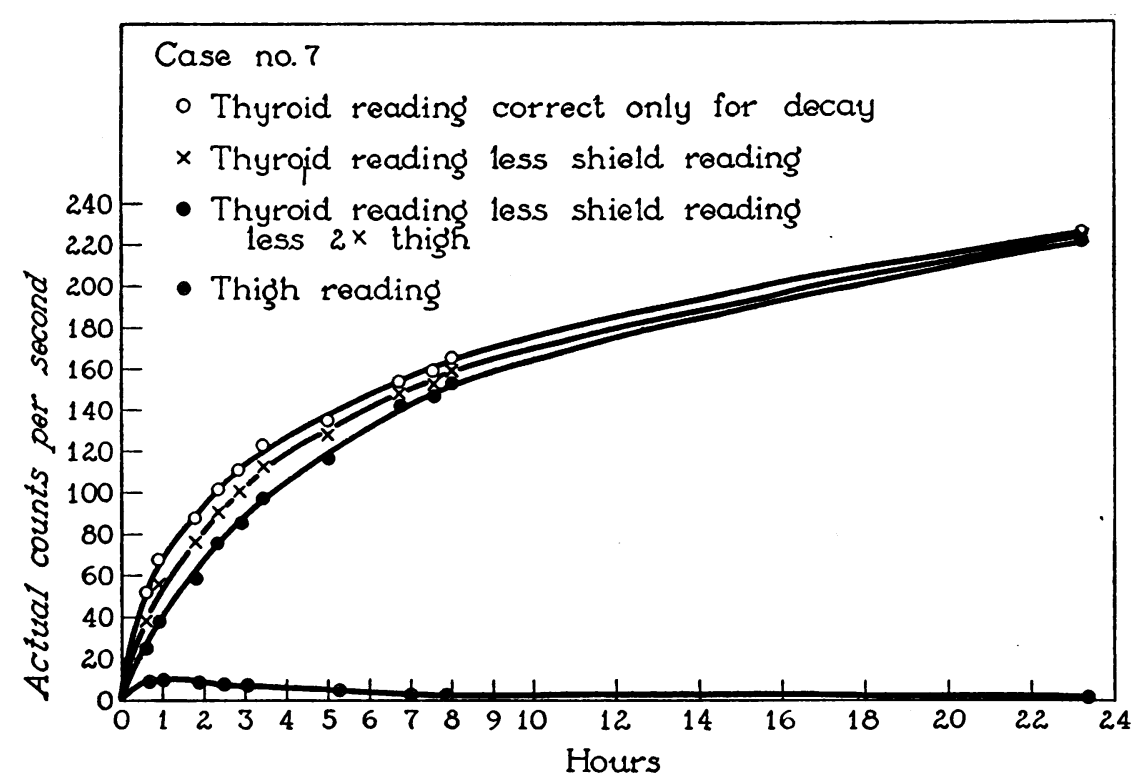

Fig. 2. Radiotodine Accumulation Curves in a Case of Ádenomatous Goiter without Hyperthyroidism Illustrating the Magnitude of the Correction for Radiation from the Body and from the Tissues of the Neck

tween the thyroid gland and the counting tube, which when in place blocked out more than 99.5 per cent of the direct gamma rays from the thyroid gland. To allow enough room to interpose the lead shield and to have the tube far enough away to receive rays from the entire gland a standard distance of $10 \mathrm{~cm}$. above the thyroid and thigh was chosen at which to place the counter tube. Readings taken with the shield were subtracted from readings without the shield. This corrected for background radiation from the entire body.

The counter tube was kept in an assembly attached to a standard so that it could be raised, lowered or turned in any direction (Figure 1). The assembly consisted of a lead cylinder with a wall $16 \mathrm{~mm}$. in thickness surrounding the counting tube. Over the window of the tube at the lower end of the assembly was a $2.7 \mathrm{~mm}$. brass filter. (Low counts were increased by using instead a filter consisting of $0.2 \mathrm{~mm}$. copper with $0.04 \mathrm{~mm}$. lead.) A pad was placed under the patient's neck so that the arch of the neck would remain constant. Adhesive tape was placed over the center of the thyroid. The tube assembly was centered over a cross on the center of the adhesive tape by using a thin brass plate, which exactly fitted the lower end of the tube assembly, and the center of which had a small chain attached to it to act as a plumb line. Readings were taken with and without the shield interposed above the thyroid and then with and without the shield above the thigh and $10 \mathrm{~cm}$. cephalad to the patella. Whenever there was considerable discrepancy between any two readings, a third or fourth reading was made. The measurements over the thigh were made primarily to correct for the radiation due to radioiodine in the extracellular fluids of the neck. Including the time for setting the tube, the time for one such series as just described which led to a single point on a graph required about 30 minutes.

The I131 was given to fasting subjects in $100 \mu \mathrm{g}$. of sodium iodide as carrier. Tracer doses of $\mathrm{I}^{181}$ consisted of about 100 to 1,700 microcuries and therapeutic doses of more than 2,500 microcuries. The neck was palpated and the center of the thyroid gland (if palpable) was marked with adhesive tape on which a cross was marked. With the patient lying face upward on a cot, readings were taken with the counter tube set $10 \mathrm{~cm}$. above the thyroid. Readings were made every 30 to 90 minutes for eight hours and daily thereafter.

In a series of seven patients who apparently did not concentrate radioiodine in their thyroid glands, it was found that the average ratio of radioactivity over the neck, compared to that over the thigh after the ratio became relatively constant, was 2.3 with a range of 2.1 to 2.6. Since in each given case the neck-to-thigh ratio would only be approximate, it was arbitrarily decided to subtract two times the reading obtained from the thigh to correct for the radioiodine in the blood and extracellular fluid in the neck. Figure 2 illustrates the magnitude of the corrections which were made for body radiation and radiation of the extrathyroid part of the neck in an average euthyroid subject. The top curve is that which was obtained when neither of these corrections was made. The second curve from the top shows the effect of correction for body radiation (subtraction of the readings over the thyroid area with the shield interposed). The third curve from the top is the one which was used routinely and was obtained by subtracting twice the values for thigh from the values plotted in the second curve from the top. In cases in which the uptake of radioiodine in the thyroid gland was larger, such cor- 
a.

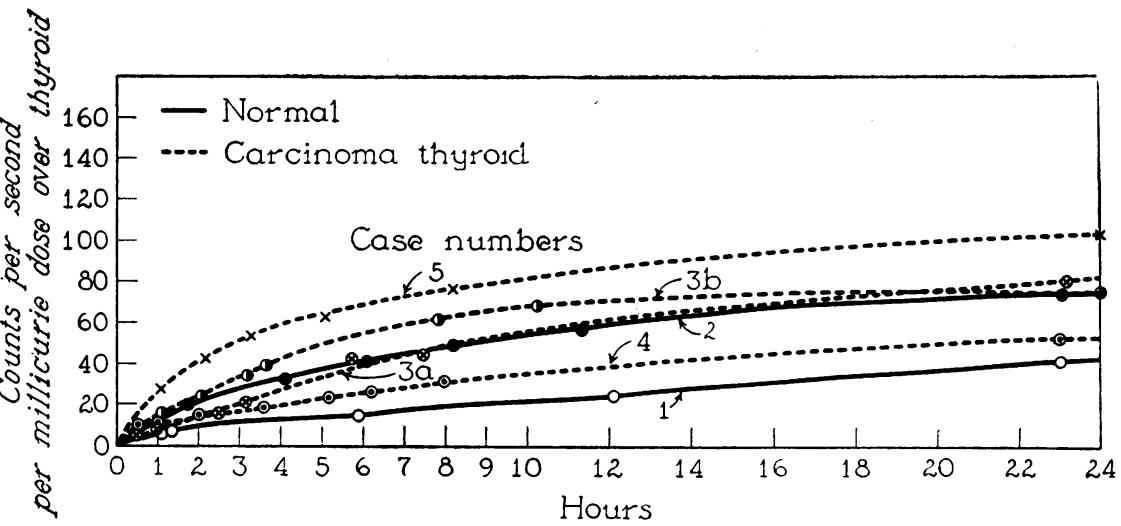

b.

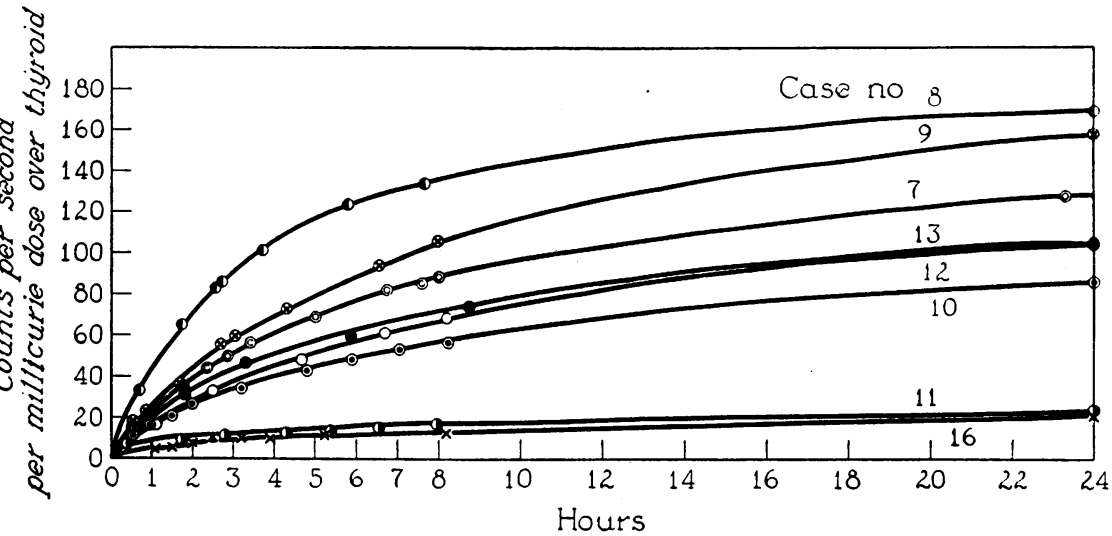

c.

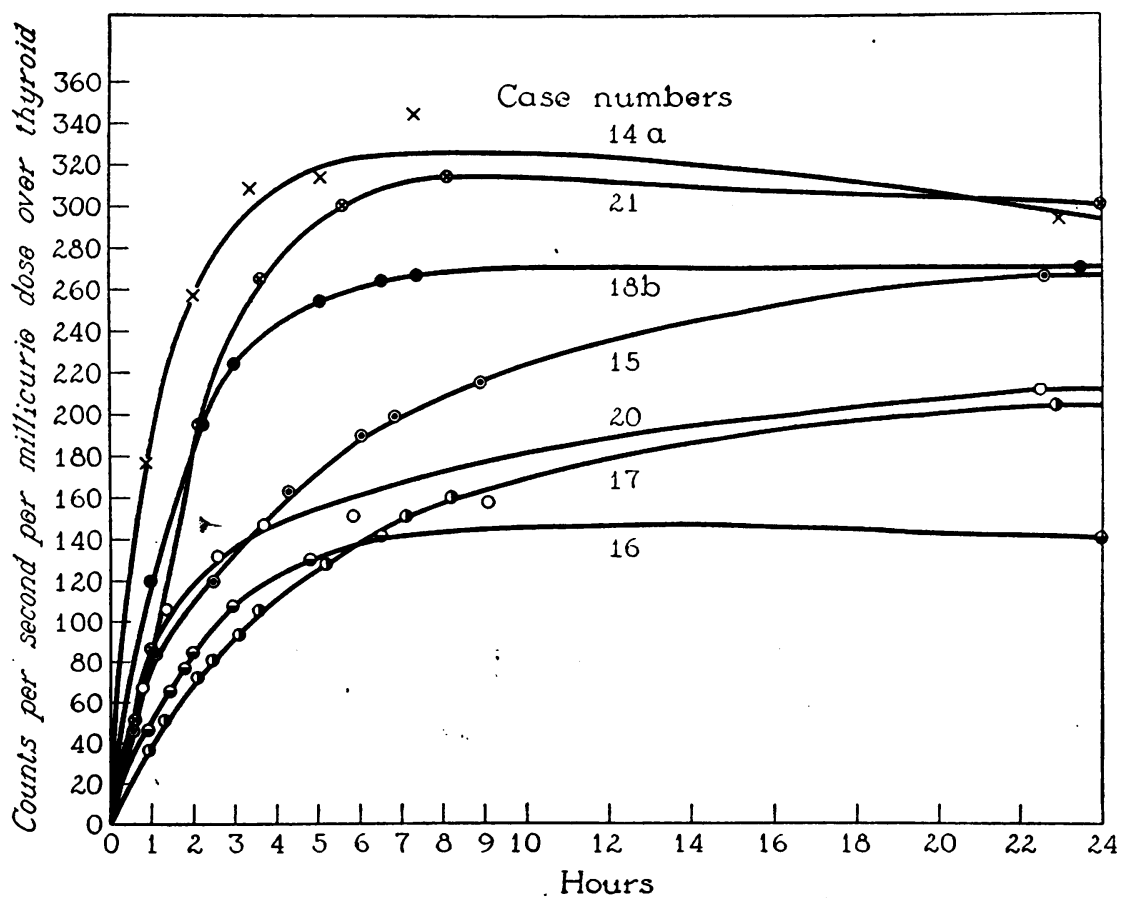

Fig. 3. Individual Curves of Accumulation of Iodine in the Thyroid

$a$. For normal volunteers and euthyroid individuals with carcinoma of the thyroid. $b$. For individuals with adenomatous goiters without hyperthyroidism. Some of these appear to collect substantially more than other euthyroid patients. c. For individuals with hyperthyroidism who received tracer doses. Curves constructed from therapeutic doses did not differ significantly. 
rections made even less difference than in the case illustrated.

For a patient receiving a large dose of $\mathrm{I}^{131}$ for therapeutic purposes, the counting tube was not able to record all the counts. It was necessary in such situations to use a lead filter in addition to the brass filter over the window of the tube. The sensitivity of the tube was checked against a radium standard. Corrections were made for the resolving time of the counting tube, the decay of the $I^{131}$, and for the various filters used.

Fourteen studies were made of 13 euthyroid subjects including two normal volunteers, three patients having carcinoma of the thyroid of low grade of malignancy and eight patients having adenomatous goiters without hyperthyroidism. Observations in one case were previously reported by Keating and his co-workers. Fifteen studies were made on ten patients who had hyperthyroidism. Six studies were made on six myxedematous patients. Studies of the blood and urine were carried out as described in previous papers $(7,8)$.

\section{RESULTS}

Figure $3 a$ shows individual iodine-accumulation curves of normal volunteers, and of euthyroid patients with thyroid carcinoma of low grade of malignancy; Figure $3 b$ shows the individual curves of euthyroid patients with adenomatous goiters, and Figure $3 c$ the individual curves of patients with exophthalmic goiters receiving tracer doses. Curves obtained in five additional cases of exophthalmic goiter after therapeutic doses and curves obtained in six cases of myxedema are not shown individually but are summarized in Figure 4. In order to place all subjects on a comparable basis as far as dosage was concerned, observations of radioactivity were expressed as counts per second per millicurie of dosage. That is, the counts per second as observed were divided by the millicuries of dosage before plotting. When different filters were used, a similar adjustment was made for the effect of the filter. Each count observed at $10 \mathrm{~cm}$. was equal approximately to 2.5 microcuries. Such adjustments for dosage and filter are valid as far as they go but comparison from case to case even with these corrections is at best a rough approximation since it takes no account of the varying shapes of the thyroid and the varying locations in the necks in different individuals.

The curves were all exponential. The curves of the normal individuals and of euthyroid patients with carcinomas or adenomas without hyperthyroidism reached their peak value in about 24 to 48 hours and, thereafter, diminished very slowly. The curves of hyperthyroid patients, whether obtained after tracer or therapeutic doses, rose more steeply and to higher peaks and, thereafter, decreased more rapidly than the curves of euthyroid persons. It made no apparent differ-

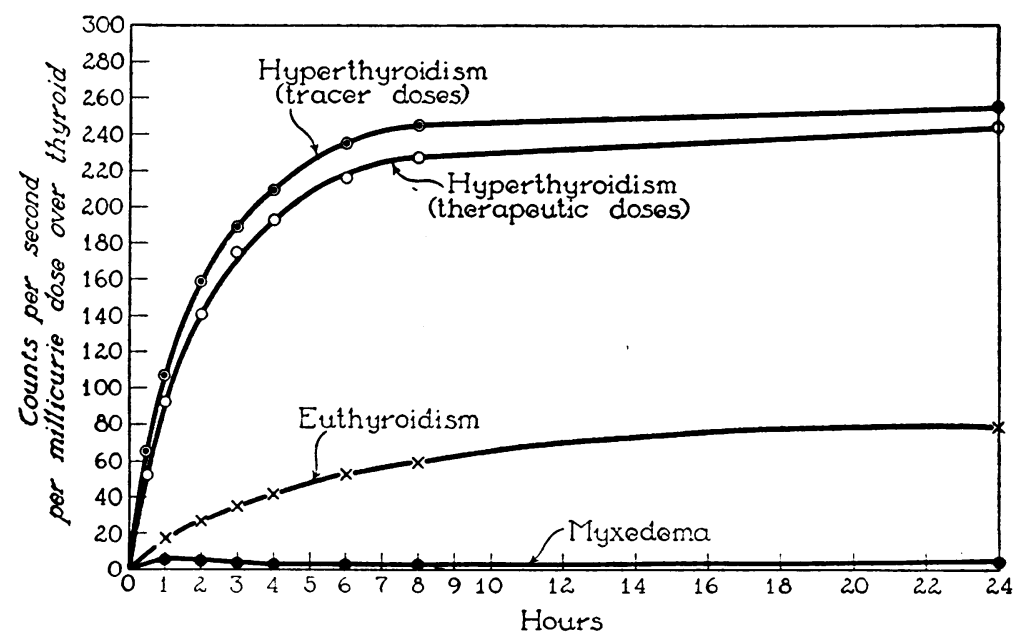

Fig. 4. Composite Accumulation Curves Constructed from the Mean Observations for Each Point in Time for Each Group

The curve for myxedema represents six cases, in none of which did the thyroids retain significant quantities of radioiodine. The curve for therapeutic doses in hyperthyroidism does not differ significantly from the curve for tracer doses, 


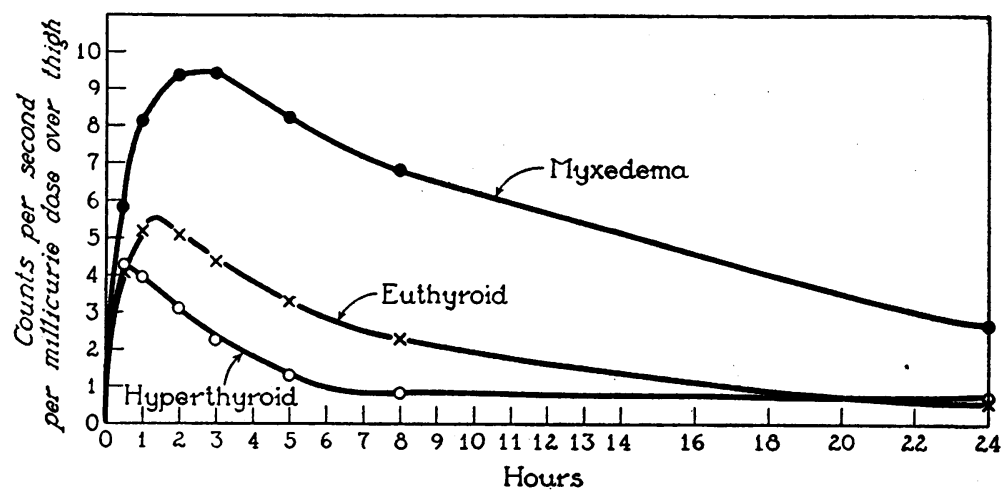

Fig. 5. Composite Curves of Radioactivity over the Thigh Constructed from the Mean Observations for Each Point in TIME For EAch Group

These curves correspond in form to those obtained by McConahey and associates by analysis of blood samples.

ence in the shape of the curves or in their apparent magnitude expressed as counts per second per millicurie whether tracer or therapeutic doses were measured. There was some overlapping between the lowest curves for hyperthyroid patients and the highest curves for euthyroid subjects. The curves obtained in cases of myxedema showed little or no accumulation of radioiodine in the thyroid.

Figure 4 shows the composite curves for each of the four types of condition studied computed from the means of the observations versus time: (1) euthyroidism, all cases, (2) hyperthyroidism with tracer doses, (3) hyperthyroidism with therapeutic doses, and (4) myxedema. The peaks in cases of hyperthyroidism were about three times as great as the peaks in cases of euthyroidism and half of the peak value was reached in less than two hours while the euthyroid curve reached half its peak value in about four hours.

Two patients were studied who clinically were thought to have hyperthyroidism but who failed to collect radioiodine. The neck-to-thigh ratio in each case was approximately $2: 1$ and in each the radiation over the neck decreased at the same rate as over the thigh. No concentration of radioactivity could be detected in the pelvis or other parts of the body.

One patient was a nervous woman, aged 33 years, whose basal metabolic rates ranged from +23 to +37 per cent. She had taken iodine for a year and had discontinued its use two weeks prior to the tracer study. At operation $6 \mathrm{gm}$. representing approximately three fourths of the thyroid was removed. It showed slight parenchymatous hypertrophy. Thyroidectomy did not relieve her symptoms.

The second patient was a women, aged 38 years, whose basal metabolic rates varied from +18 to +23 per cent. Biopsy of the skin disclosed lupus erythematosus; the spleen was enlarged, and the thyroid was not palpable. A cholecystogram had been made 12 days before radioiodine was given. No improvement followed a therapeutic trial of Lugol's solution. Thyroidectomy was not performed.

In Figure 5 composite curves of observations over the thigh are plotted as counts per second per millicurie of dose against time in hours. The conditions studied were (1) euthyroid state in 11 cases; (2) hyperthyroidism in 11 cases, and (3) myxedema in six cases. The curve for patients who had hyperthyroidism had the lowest peak. This was reached within 30 minutes after observations were begun and values, thereafter, decreased the most rapidly of any of the three groups; that is, it decreased to one half of its peak value in two and a half to three hours. The curve for euthyroid patients reached its peak in one hour, at a higher level, and fell more slowly, reaching its half value in about six hours after the peak was reached. Finally, the curve for myxedematous patients indicated that the peak of radioactivity in the blood and extracellular fluid was not reached until about two to three hours after oral administration of $I^{181}$. This peak was 
the highest of the three, and half of the peak value was reached in about 11 to 13 hours. The counts from the thigh with small tracer doses were small and inaccurate owing to the low level of radioactivity. The similarity between curves of measurements from the thigh and from the blood was most striking.

\section{COM MENT}

Observations with a Geiger counter, and in particular observations in vivo, are subject to numerous sources of error. These include variations in the sensitivity and stability of the counter tube, a statistical counting error which varies with the counting rate as compared to the background count and in the case of high counts a systematic error resulting from the resolving time of the tube. Such purely physical errors can be corrected or minimized by careful technic, but despite the utmost care such errors place a definite limit on the precision of in vivo counting. Other errors arise from a consideration of the varying size and shape of the thyroid and surrounding structures in different individuals, variations in radiation entering the apparatus from other parts of the body than that being measured and so forth. To a certain extent these too can be minimized but not eliminated by careful technic. It is impossible to express quantitatively the net error in the observations which result from the sum of the foregoing and the efforts to minimize them. Such errors become especially important when an attempt is made to measure radioactivity in some absolute term, but even in the present case, in which radioactivity is measured in counts per second, at various intervals of time, one must regard the observations as having an error of the order of magnitude of perhaps 10 per cent. Minor fluctuations, therefore, might easily occur in the quantity of radioiodine in the thyroid which could not be detected by this method.

Inspection of the curves in Figure 3 indicate that, as shown by other observers, the hyperplastic thyroids of hyperthyroid patients accumulate much larger quantities of radioiodine and do so more rapidly than do the thyroids of euthyroid individuals. It is unfortunate that a larger group of normal persons were not available for comparison. We have been reluctant to perform radioiodine studies on more normal volunteers at the

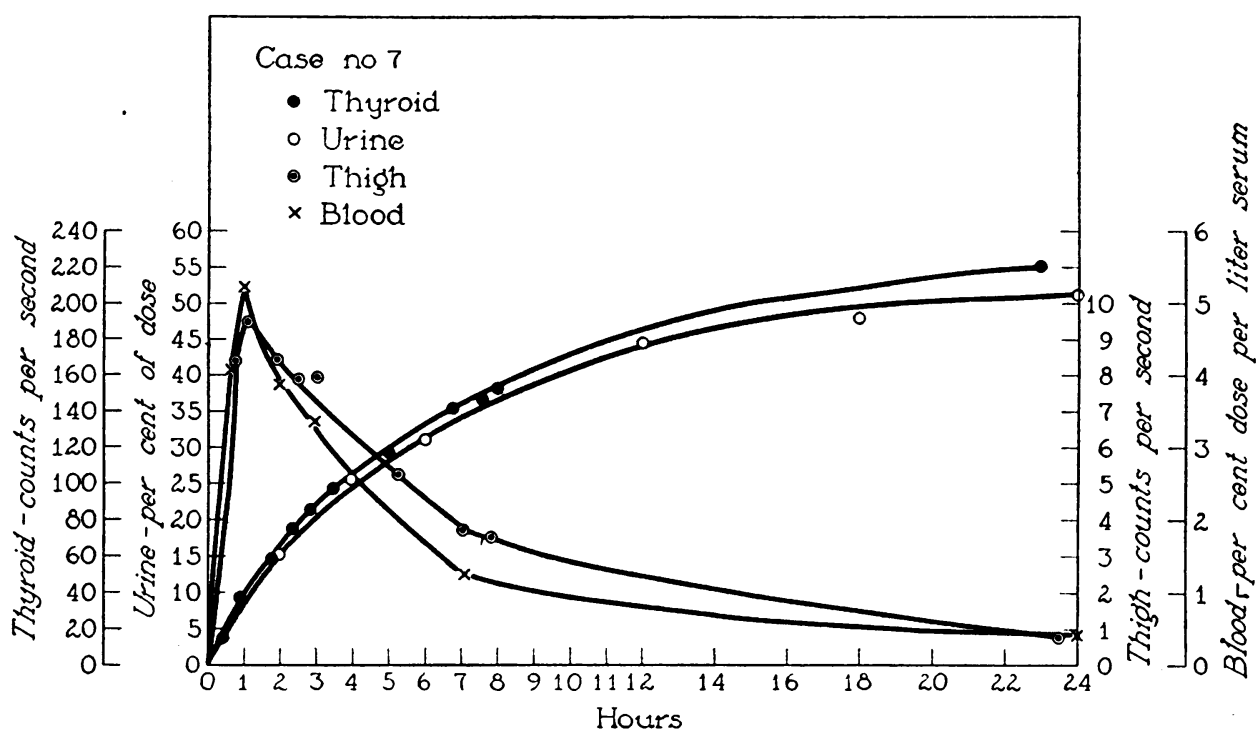

Fig. 6. Curves Denoting Accumulation of Radioiodine in a Case of Adenomatous GOITER WITHOUT HYPERTHYROIDISM

Curves were constructed from simultaneous observations made over the thyroid and the thigh and analyses for radioiodine in samples of blood and urine. Note that thyroid and urine curves are similar in form and that blood and thigh curves resemble each other closely. That all four have a common denominator is indicated by the fact that all tend to level off at about the same time. 
doses which present technics require because of a growing concern over the quantity of radiation involved. This may be of the order of 12 roentgens equivalent physical (r.e.p.) per day initially and a total integrated dose of the order of 150 r.e.p. when 100 microcuries of $\mathrm{I}^{131}$ are given. So far as our observations show, the thyroids of euthyroid individuals with thyroid malignancy of low grade behave in an essentially normal fashion, as do most thyroids of euthyroid individuals with small or moderate adenomatous goiters without hyperthyroidism. For purposes of comparison with hyperthyroid and hypothyroid patients these have been included. In the cases of malignant disease of the thyroid included in this study the malignant tissue, so far as could be determined, did not collect a measurable amount of radioiodine. In a large group of cases of adenomatous goiter without hyperthyroidism in which the urinary excretion of radioiodine was studied, considerably more variation in the behavior of the radioiodine occurred than in other euthyroid groups. A certain proportion of the thyroid glands of these patients, particularly the large nodular goiters, behaved more like hyperthyroid than euthyroid glands. The radioiodine-accumulation curves of the adenomatous goiters without hyperthyroidism included in the present study (Figure $3 b$ ) in general resembled those of normal subjects and euthyroid patients with malignant lesions, although several patients retained larger quantities of iodine in their thyroids. One patient in particular (Case 8 , Figure $3 b$ ) collected more iodine and did so more rapidly than any other euthyroid individual studied. It is probable, therefore, that adenomatous goiters, especially large ones, ought not to be regarded as entirely normal in function even in the absence of clinical hyperthyroidism.

The form of the curve of accumulation of iodine in the thyroid appears on inspection to be exponential and resembles closely the curves constructed from observations of urinary excretion in a previous paper. Furthermore, the form of the curve of radioactivity over the thigh corresponds closely to that constructed from determinations of radioiodine in blood serum. Figure 6 illustrates the relationships of all four types of observations in a case of adenomatous goiter without hyperthyroidism. The existence of a rate constant common to all four curves can be inferred from the fact that they all tend to level off at about the same time. It is of interest, therefore, to analyze these curves in the manner employed by Keating, Power, Berkson and Haines (7) for the study of urinary excretion of radioiodine.

\section{ANALYSIS OF CURVES}

Observations of the quantity of radioiodine in the thyroid can be fitted with an exponential function of the form

$$
Q_{\text {thyrold }}=Q_{t}=Q_{t f}\left(1-e^{-r t}\right)
$$

where $Q_{t}$ is the quantity of radioactivity expressed as counts per second in the thyroid at any time, $Q_{u}$ the asymptotic (time $=$ infinity) value of the function $Q_{t}$, and $r$ a rate constant. Similarly the descending portion of the observations made over the thigh can be fitted with an exponential function of the form

$$
Q_{\text {thigh }}=Q_{0}=Q_{.0}\left(e^{-r t}\right)
$$

where $Q_{0}$ is the quantity of radioactivity in counts per second at time $t$ and $Q_{00}$ is the value of the function corresponding to $t=0$. The parameters $Q_{t}$ and $r$ for the thyroid curve were evaluated by the method previously described, consisting of plotting $\log \left(Q_{t}, Q_{t}\right)$ against $t$ for various estimated values of $Q_{t f}$ until the relationship fits a straight line, and from the slope of this line evaluating $r$. In the case of the curve for the observations of the thigh, the parameters $Q_{.0}$ and $r$ are evaluated from a straight line fitted to the plot of $\log Q$. against $t$.

Table I shows the values for the rate constant $r$ as evaluated in the same patients from (1) the curves of accumulation of radioiodine in the thy-

TABLE I

Values for the rate constant $\mathrm{r}$ determined from urine,

\begin{tabular}{|c|c|c|c|c|c|c|}
\hline \multirow{2}{*}{ Condition } & \multirow{2}{*}{ Cases } & \multicolumn{3}{|c|}{$r$ (per cent per hour), mean* } & \multicolumn{2}{|c|}{ Variability of $r t$} \\
\hline & & Urine & Thyroid & Thigh & $\begin{array}{l}\text { (S.D. })^{2} \\
\text { vari- }\end{array}$ & $\mathbf{P}$ \\
\hline $\begin{array}{l}\text { Euthyroid } \\
\text { Hyperthyroid } \\
\text { Hypothyroid }\end{array}$ & $\begin{array}{r}14 \\
15 \\
6\end{array}$ & $\begin{array}{l}13.8 \pm 0.9 \\
37.9 \pm 3.3 \\
5.93 \pm 0.3\end{array}$ & $\begin{array}{l}13.5 \pm 0.9 \\
40.3 \pm 3.7 \\
6.10 \pm 0.5\end{array}$ & $\left|\begin{array}{l}14.4 \pm 1.0 \\
36.2 \pm 3.1 \\
6.65 \pm 0.6\end{array}\right|$ & $\begin{array}{r}3.18 \\
26.73 \\
0.70\end{array}$ & $\begin{array}{l}>0.05 \\
>0.05 \\
>0.05\end{array}$ \\
\hline
\end{tabular}
thyroid and thigh

* The value after the \pm is the standard error of the mean.

$\dagger$ The variability of $r$ for each case was calculated as the variance (squared S.D.) of the three estimates derived (urine, thigh, thyroid); the value in the table is the mean variance for the group. The $P$ value was calculated by the method of analysis of variance (10) to determine whether the differences among the determined $r$ 's were significant statistically. A value of $P<0.05$ is generally considered a good criterion of significance. (For none of the groups was it indicative that the r's determined in the different ways were different.) 
TABLE II

Values for rate constant $\mathrm{r}$ determined from urine, blood, thyroid and thigh

\begin{tabular}{|c|c|c|c|c|c|c|c|}
\hline \multirow{2}{*}{ Condition } & \multirow{2}{*}{ Cases } & \multicolumn{4}{|c|}{$r$ (per cent per hour), mean* } & \multicolumn{2}{|c|}{$\begin{array}{c}\text { Variability } \\
\text { of } r \dagger\end{array}$} \\
\hline & & Urine & Blood & Thyroid & Thigh & $\begin{array}{c}(\text { S.D. })^{2} \\
\text { vari- } \\
\text { ance }\end{array}$ & $\mathbf{P}$ \\
\hline $\begin{array}{l}\text { Euthyroid } \\
\text { Hyper- } \\
\text { thyroid } \\
\text { Hypo- } \\
\text { thyroid }\end{array}$ & $\begin{array}{l}6 \\
7 \\
4\end{array}$ & $\begin{array}{r}14.5 \pm 1.1 \\
39.0 \pm 5.3 \\
6.0 \pm 0.5\end{array}$ & $\begin{array}{r}15.0 \pm 0.8 \\
39.3 \pm 5.5 \\
8.5 \pm 1.3\end{array}$ & $\begin{array}{r}12.9 \pm 1.1 \\
40.6 \pm 6.6 \\
6.0 \pm 0.7\end{array}$ & $\begin{array}{r}14.0 \pm 1.0 \\
37.0 \pm 5.1 \\
6.9 \pm 0.5\end{array}$ & $\begin{array}{r}3.76 \\
26.84 \\
2.68\end{array}$ & $\begin{array}{l}>0.05 \\
>0.05 \\
>0.05\end{array}$ \\
\hline
\end{tabular}

* The value after the \pm is the standard error of the mean.

$\dagger$ The variability of $r$ for each case was calculated as the variance (squared S.D.) of the four estimates derived (urine, blood, thigh, thyroid); the value in the table is the mean variance for the group. The $P$ value was calculated by the method of analysis of variance (10) to determine whether the differences among the determined $r$ 's were significant statistically. A value of $\mathrm{P}<0.05$ is generally considered a good criterion of significance.

roid, (2) observations over the thigh, and (3) analysis of urinary excretion. Table II shows a similar comparison in those cases included in the first table in which, in addition to the foregoing, the concentration of radioiodine in blood also was determined. It appears from the analysis in both tables that the rates obtained by these various methods are not significantly different from one another either in the individual cases or when the means for the various groups are compared. The actual values obtained in an individual case do show some random variation from one method to another which can be ascribed to the errors in the analytical methods employed and in addition to inaccuracies arising from the methods of curve fitting employed for the estimation of the rates. The rate as determined from analysis of the thyroid curve is the same as that obtained from observations over the thigh, on the urine and on the blood. It is not a measure of thyroidal accumulation rate, but like the rate constant derived from urine represents the proportional rate of disappearance of radioiodine from blood. This follows from the same analysis on which the previous calculations of Keating and associates were based. The rate of disappearance of radioiodine from blood, however estimated, usually varies according to the state of thyroidal activity. No matter how measured it is not a quantitative or direct measure of accumulation of iodine in the thyroid gland, since it must measure the rate at which iodine disappears from the blood into all sites of disposal including the urine and other tissues as well as the thyroid.

\section{SUMMARY}

A method is described for making relative in vivo measurements of the quantity of radioiodine accumulated by the thyroid. Accumulation of radioiodine by the thyroid has been measured in 29 individuals having various states of thyroidal function. These measurements have been compared with observations over the extremities (thighs), with measurements of urinary excretion and with analysis of blood for radioiodine.

In vivo observations over the thyroid show substantially more radioiodine accumulated by the thyroids of hyperthyroid individuals than by the thyroids of euthyroid individuals. Euthyroid patients with nodular goiters may at times collect more radioiodine in their thyroids than other euthyroid subjects. Hypothyroid patients show little or no accumulation of iodine in their thyroids.

The accumulation of radioiodine by the thyroid was observed to follow an exponential curve similar in form to the curve of urinary excretion of radioiodine. Observations of radioactivity over the thigh, on the other hand, resembled closely curves constructed from analyses of radioiodine in serum.

Estimation of the exponential rate constant of the curve of radioiodine accumulation by the thyroid was found to have the same value as the rate constant estimated from observations over the thigh, from observations of urinary excretion or from analyses of blood for radioiodine. This rate is regarded as representing the rate of disappearance of radioiodine from blood no matter which method is used to obtain it.

The rate of disappearance of radioiodine from blood varies according to the state of thyroidal activity. Even when obtained directly from observations on the thyroid in vivo, however, it does not provide a direct or quantitative measure of the accumulation of radioiodine by the thyroid, since it must measure the rate of disappearance of radioiodine from the blood into all sites of disposal, including the urine and other tissues as well as the thyroid. 


\section{BIBLIOGRAPHY}

1. Hamilton, J. G., and Soley, M. H., Studies in iodine metabolism of the thyroid gland in situ by the use of radio-iodine in normal subjects and in patients with various types of goiter. Am. J. Physiol., 1940, 131, 135.

2. Hamilton, J. G., Use of radioactive tracers in biology and medicine. Radiology, 1942, 39, 541.

3. Hamilton, J. G., Soley, M. H., Reilly, W. A., and Eichorn, K. B., Radioactive iodine studies in childhood hypothyroidism. Am. J. Dis. Child., 1943, 66, 495.

4. Hertz, Saul, Radioactive iodine as indicator in thyroid physiology; observations on rabbits and on goiter patients. Am. J. Roentgenol., 1941, 46, 467.

5. Quimby, Edith H., and McCune, D. J., Uptake of radioactive iodine by the normal and disordered thyroid gland in children. Radiology, 1947, 49, 201.
6. Stanley, M. M., and Astwood, E. B., Determination of the relative activities of antithyroid compounds in man using radioactive iodine. Endocrinology, 1947, 41, 66.

7. Keating, F. R., Jr., Power, M. H., Berkson, Joseph, and Haines, S. F., The urinary excretion of radioiodine in various thyroid states. J. Clin. Invest., 1947, 26, 1138.

8. McConahey, W. M., Keating, F. R., Jr., and Power, M. H., The behavior of radioiodine in the blood. J. Clin. Invest., 1949, 28, 191.

9. Seidlin, S. M., Marinelli, L. D., and Oshry, Eleanor, Radioactive iodine therapy; effect on functioning metastases of adenocarcinoma of the thyroid. J. A. M. A., 1946, 132, 838.

10. Snedecor, G. W., Statistical Methods Applied to Experiments in Agriculture and Biology. The Iowa State College Press, Ames, Iowa, 1940, 422 pp. 